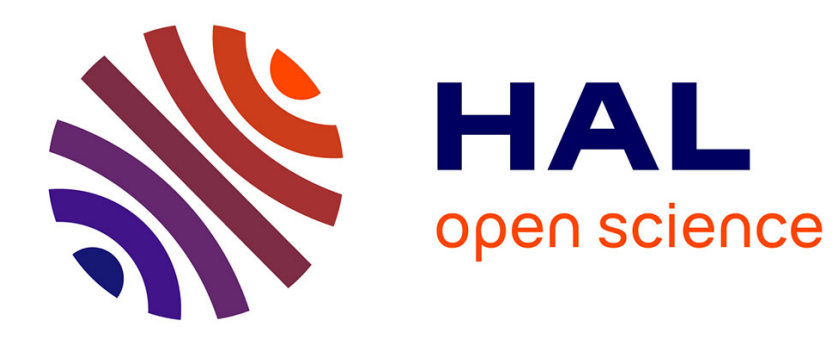

\title{
STRUCTURE AND PROPERTIES OF CREEP SUBBOUNDARIES
}

J. Martin, M. Morris, M. Carrard

\section{To cite this version:}

J. Martin, M. Morris, M. Carrard. STRUCTURE AND PROPERTIES OF CREEP SUBBOUNDARIES. Journal de Physique Colloques, 1985, 46 (C4), pp.C4-417-C4-422. 10.1051/jphyscol:1985445 . jpa-00224696

\section{HAL Id: jpa-00224696 https://hal.science/jpa-00224696}

Submitted on 1 Jan 1985

HAL is a multi-disciplinary open access archive for the deposit and dissemination of scientific research documents, whether they are published or not. The documents may come from teaching and research institutions in France or abroad, or from public or private research centers.
L'archive ouverte pluridisciplinaire $\mathbf{H A L}$, est destinée au dépôt et à la diffusion de documents scientifiques de niveau recherche, publiés ou non, émanant des établissements d'enseignement et de recherche français ou étrangers, des laboratoires publics ou privés. 


\author{
J.L. Martin, M. Morris and M. Carrard \\ Institut de Génie Atomique, EPFL, CH-1015 Lausanne, Switzerland
}

Résumé - On décrit les propriétés des sous-joints de fluage à partir d'observations et expériences diverses réalisées dans un microscope électronique dans de l'aluminium et un alliage aluminium-zinc. Leur géométrie, champs de contraintes associés, leurs propriétés dynamiques et leur rôle dans la résistance au fluage sont examinés.

Abstract - The properties of creep subboundaries are described as derived from observations and experiments in the electron microscope for aluminium and an aluminium-zinc alloy. Their geometry, associated stress fields, their dynamic properties and their contribution to the creep strength are reviewed.

Among the different types of interfaces, subboundaries are simple ones. At low misorientations at least, the constituant dislocations are visible by means of conventional electron microscopy and several of their properties can be known. The present paper reports the characteristics of subboundaries which develop during stage II of creep in Aluminium and an Al-Zn alloy. The static properties (detailed geometrical description), dynamic ones (mobility...), and their connection with the constitutive equations of creep are studied here below.

\title{
EXPERIMENTAL DETAILS
}

The results presented here were obtained, using $99.99 \%$ Al single crystals in the 112 orientation, crept at $150^{\circ} \mathrm{C}$ and $400^{\circ} \mathrm{C} / 1 \%, 99.3 \%$ pure $\mathrm{Al}$ in polycrystali ine sheets of $.5 \mathrm{~mm}$ thickness tested between 80 and $200{ }^{\circ} \mathrm{C} / 2 /$, and $\mathrm{Al}-11 \mathrm{wt} \% \mathrm{Zn}$ cylindrical polycrystals crept at 210 and $215{ }^{\circ} \mathrm{C} / 3 /$. All were deformed in tension up to stage II of creep. Conventional electron microscope studies were carried out (TEM and SEM), as well as in situ creep experiments in a high voltage electron microscope (HVEM) /4, 5/ and dislocation pinning experiments in the load applied state $/ 3 /$ in $A T-Z n$. The latter techniques provide useful informations about the substructure properties under load, and are very complementary $/ 6 /$.

\section{SUBBOUNDARY STRUCTURE}

The possible geometries of subboundaries (i.e. periodic networks with no long range stress fields) are anaiyzed in detail, in $/ 7 \%$. The first experimental observations of subboundaries were performed by decoration techniques in $\mathrm{NaCl}$ and $\mathrm{KCl}$ $/ 8 /$.

Creep subboundaries appear in stage II, when the crystal is divided into subgrains of several microns in diameter.

In the single crystals $/ 1 /$, the symmetrical orientation with respect to glide, develops at $150^{\circ} \mathrm{C}$ a characteristic substructure illustrated on fig. 1 . A crossgrating of two types of cylinders approximately parallel to the directions of the primary Burgers vectors (i.e. [101] and [011]) appears on a (111) longitudinal section. The (112) normal cross section shows that the corresponding crystal blocks are elongated along the [11I] direction. They are misoriented by 1 or 
$2^{\circ}$ with respect to each other, around [21I] and [12I] respectively. They are rotated alternatively in the positive and negative directions around these axes, so as to maintain the symmetrical sample orientation as it is strained. They are divided into smaller subgrains as seen in TEM, with weak relative misorientations (smaller than $.5^{\circ}$ ). Some of the subboundaries between the cylinders have been analysed. They appear as periodic dislocation networks. Some networks appear to be of pure twist type, lying in the (11I) plane with 3 Burgers vectors at $120^{\circ}$. The mesh sizes are of the order of some $100 \AA$. A more complete identification of the other types of subboundaries is underway.

At $400^{\circ} \mathrm{C}$, on the contrary, the temperature is high enough to allow glide on the unusual [110] (001) slip system as evidenced by the slip lines at the sample surface. Since it has a higher Schmid factor than the 111 primary systems of intermediate temperatures, it is priviledged at $400^{\circ} \mathrm{C}$. A rotation of the lattice occurs around [110], as expected in single glide, and the tensile axis evolves from [112] towards [111]. The subgrains appear as flat blocks paralle t to (110) planes as evidenced by SEM on (110) sections (see the stereographic projection of Fig. 1). Subboundaries exhibit higher tilt angles than previously $\left(5\right.$ to $\left.6^{\circ}\right)$. The dislocations are therefore much closer to each other (around $20 \AA$ ) and more difficult to identify but seem to belong to tilt boundaries with [1I0] as rotation axis ( $M$. Carrard, to be published).

In the Aluminium sheets crept at intermediate temperatures, the following features of subboundaries were obtained /2/:

- Pure tilt boundaries, or pure twist ones consisting of a square grid of two screw dislocation families are observed but seldom.

- Boundaries of mixed character, with 3 Burgers vectors at $120^{\circ} \mathrm{C}$ are the most frequent ones, lying in a variety of planes. The dislocation segments appear to lie in their respective slip planes and the general configuration of the networks is presented on fig. 2 a.

- The Frank formula which expresses that a dislocation array does not exnibit any long range stress field, seems to be satisfied for the periodic sections of the networks. This condition together with the previous ones can lead to various extreme subboundary configurations as the subboundary plane is rotated away from the Burgers vectors plane (see fig. $2 b, c, d$ ). The equilibrium of line tensions at nodes in the network is thus not fullfilled. This indicates that in aluminium at least, the weak dislocation dissociation decreases the core energy by a larger amount than the subsequent increase of line energy $/ 9 /$. Some of these configurations had been predicted by Ball and Hirsch $/ 10 /$.

In the $A 1-2 n$ polycrystal, subboundaries were also observed. They have been analysed and most of them consist of 5 dislocation families $/ 3 /$. An examples is shown on fig. 3. It was also observed that the misorientation across subgrains increases with strain $/ 3 /$ in agreement with other measurements $/ 12 /$.

Thus, according to the type of sample and creep conditions, subboundaries consisting of one to five dislocation families (out of 6 possible ones in the FCC structure) are present. This can be explained by the particular geometry of the single crystal, the various deformation compatibility requirements in the polycrystals; they are two dimensional in the sheet case and more severe for the cylindrical samples of Al-Zn.

\section{SUBBOUNDARY STRESS FIELDS}

As mentioned above, they were already checked through the Frank criterion. A different experimental approach has been developped as well $/ 11 /$. When it is possible to pin the dislocation arrangements under load, defects exhibit bowed shapes under the effects of the local or effective stresses present in the crys- 

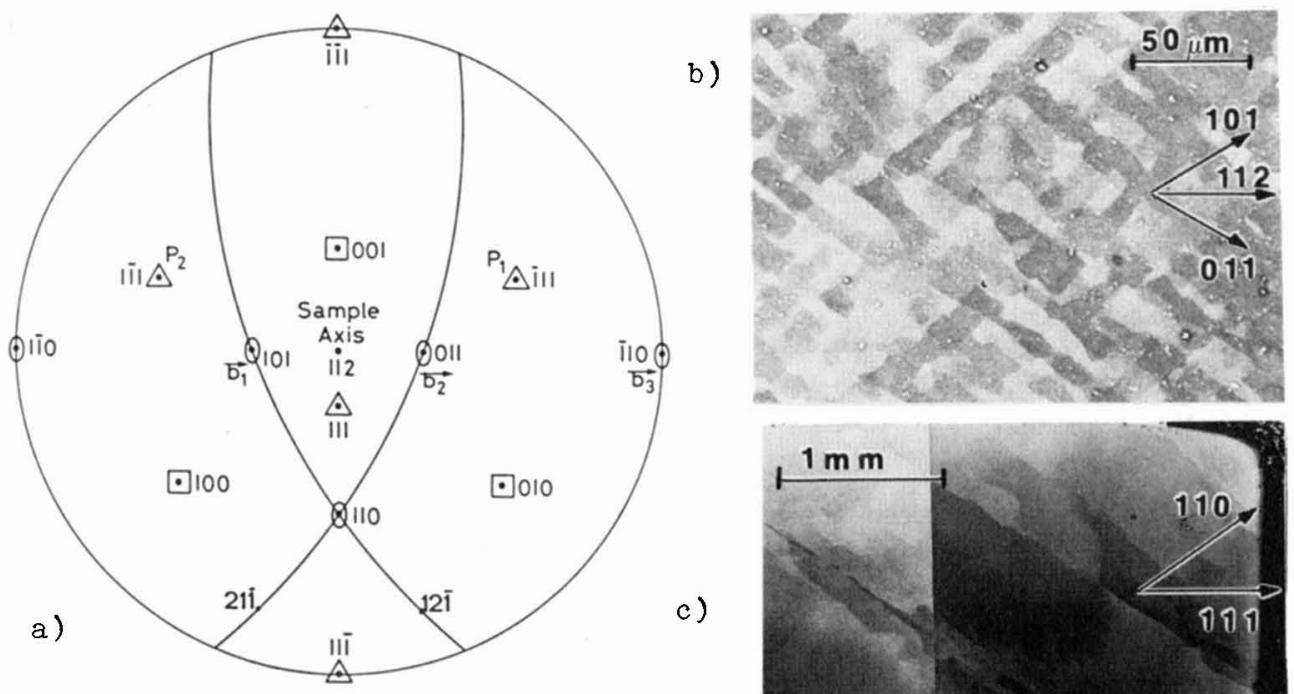

)
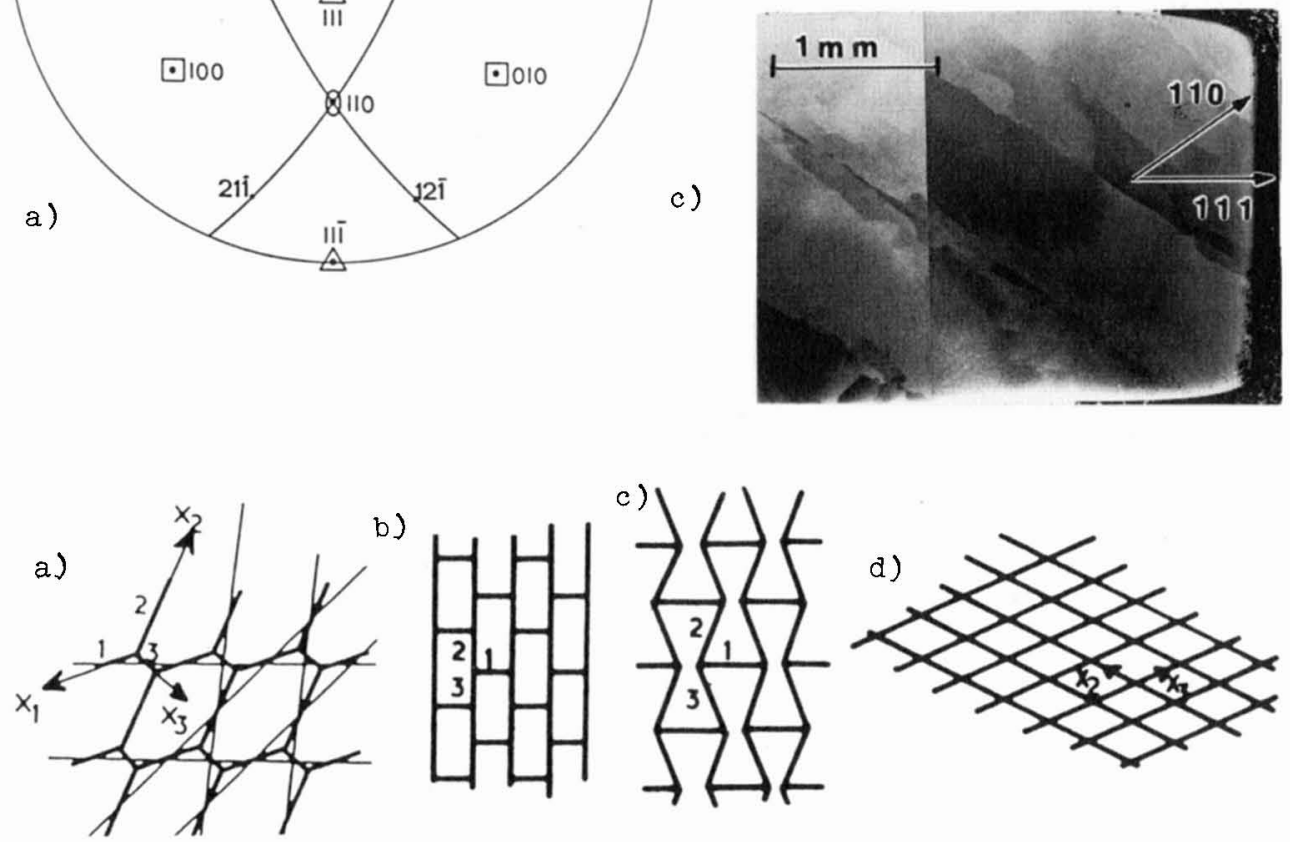

b)
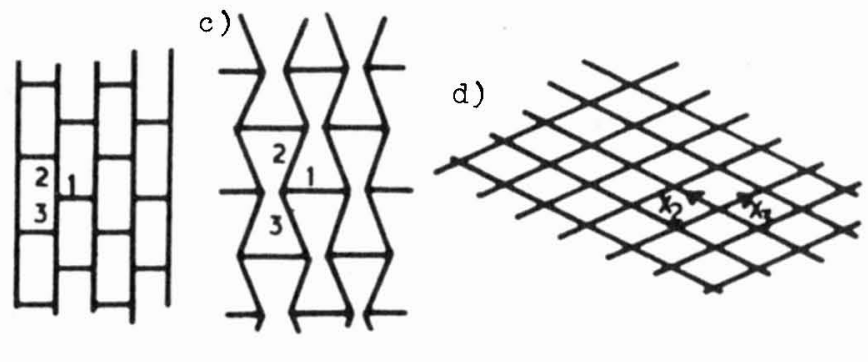

Fig. 2 - Sketch of subboundaries with 3 bs at $120^{\circ}$. a) general case; b), c), d) extreme possible cases $/ 18 / . X_{1}, X_{2}, X_{3}$ dislocation segments.

tal. The following technique was used in the case of $A 1-Z n$. At creep temperatures of 210 or $250^{\circ} \mathrm{C}$, the zinc is in solid solution and the alloy creeps in the same way as aluminium (i.e. forming subgrains). The pinning technique used, consists in quenching and ageing the specimen under load such that zinc precipitates onto the dislocations to freeze them as they are during the creep test /1/. The sample is then unloaded and foils are prepared for TEM. From the dislocation curvatures, orders of magnitude of local effective stresses can be derived.

They were measured at the subboundary and as one moves away from it towards the subgrain interior. Results are presented on fig. 4, which were obtained from several subgrains after creep at $250^{\circ} \mathrm{C}$ under an applied stress of $2.4 \mathrm{MPa}$ and at a strain of $7 \%$. The sign of the local stress has not been measured and all values are plotted as positive. It appears that very high local stresses exist at given points of the subboundaries, several times larger than the applied stress and these decrease as a function of the distance from it. In addition, a given subboundary exhibits a limited number of points with a highly concentrated stress, if 


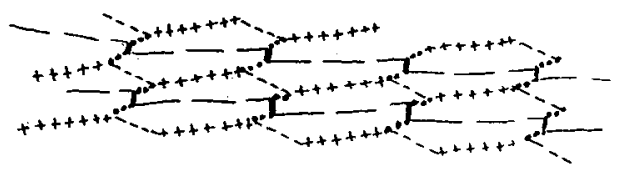

Fig. 3 - Sketch of a subboundary with 5 disiocation families as observed in Al-Zn.

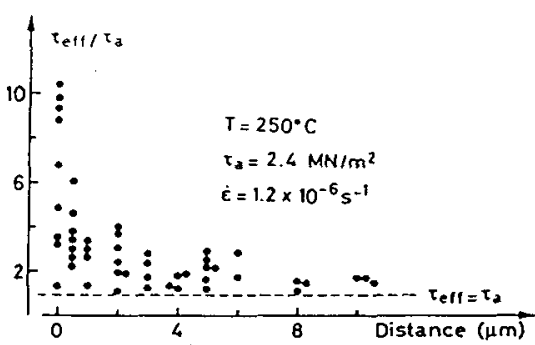

Fig. 4 - Normalized local stresses around subboundaries. $\varepsilon=7 \% / 3 /$.

any $/ 11 \%$. It has also been observed that the maximum values of local stresses in subboudaries increase as strain increases, for given creep conditions, as stress increases for a given temperature and strain and as temperature increases for a given stress and strain /13/. It therefore appears that as dislocations are heterogeneously stored in the crystal, a non homogeneous stress distribution is built up. It is thought that these areas of high effective stresses correspond to points at which the periodicity of the subboundary network is interrupted as a result of deformation: extrinsic dislocations enter the network while others are leaving it thus altering its regularity.

\section{DYNAMIC PROPERTIES OF SUBBOUNDARIES}

These were observed during in situ creep experiments performed in a HVEM /4/: the aluminium polycrystalline sheets were submitted to macroscopic creep tests. Then, microsamples were cut out of them, with the same tensile axis, and further deformed in the microscope at the same temperature and strain rate as in stage II of the preceding test.

The destruction of subboundaries (as well as their formation) is sometimes observed. Some examples have been reported previously /14/ in which, a square grid of screw dislocations (pure twist boundary in a 100 plane) was destroyed: the applied stress pulled both dislocation families apart ou their glide planes of (110\} type. But numerous experiments performed under similar conditions have shown that this phenomenon occurs rather seldom. In addition the newly emitted dislocations account for less than $1 \%$ of the total strain. However, the migration of subboudaries is more commonly observed. This process has been evidenced a long time ago in the experiments of Washburn and Parker /15/. An extensive study was undertaken by Exell and Warrington, during creep of Aluminium between 400 and $600{ }^{\circ} \mathrm{C}$, using $X$ ray topography and a Nomarski interferometer $/ 16 /$. It also occurs at lower temperatures as seen during in situ straining. The dislocation traces visible at the foil surface behind the moving boundaries, indicate that its constituent segments move by glide. Migration takes place over large distances (a significant fraction of the subboundary diameter) with a low speed $\left(10^{-4}\right.$ to $10^{-1}$ $\mu / \mathrm{mn}$ ). The dislocation segments having 3 Burgers vectors at $120^{\circ}$ (see above), two families glide in different $\{111\}$ planes while the third one glides in a $\{100\}$ type plane. Indeed there are not three intersecting 111 planes in the FCC structure. The geometry of this glide process is sketched on Fig. 5.

The locus of the boundary nodes are $\langle 011\rangle$ directions which as a rule, are not perpendicular to the network plane. Therefore the nodes move along this plane during migration so that the constituent dislocations move towards triple junctions, are crossing through them and are continuousiy transferred from one subboundary to the adjacent one. This complex three dimensional glide mechanism, which involves a cooperative slip on three different planes, is possible in this case because 3 dislocation families only are involved. 
In the Al-Zn polycrystal, migration has been observed too $/ 11 /$. The surface tilts connected to it were observed by straining a specimen to $15 \%$, polshing it and restraining it another $2 \%$. The surface was examined using Nomarski interference contrast. An example of such observations can be found in $/ 17 /$. In this case, since subboundaries consist of five dislocation families as reported above, and that they are not always situated in glide planes, migration cannot occur by glide only.

Under these various experimental conditions, the amount of strain due to migration could be estimated. It is always a small fraction of the total strain i.e. 5 to $10 \%$ in agreement with other measurements $/ 16 /$.

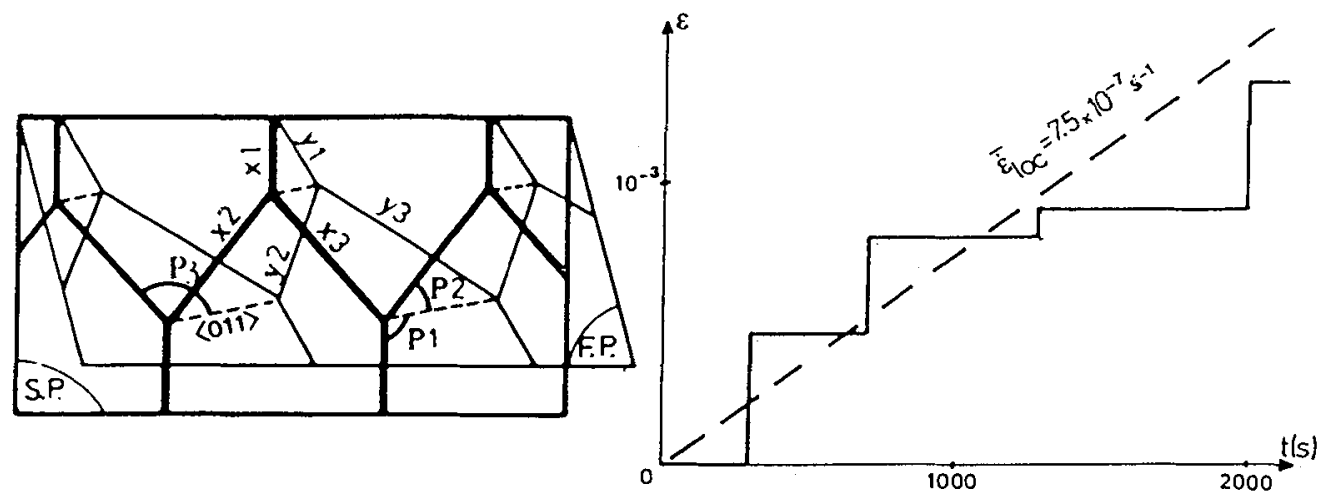

Fig. 5 - Scheme of subboundary migration. $\mathrm{SP}$ and FP: subboundary and foil planes. $X_{i}$ : dislocation segments. $P_{j}, y_{j}$ : corresponding slip planes and slip traces $/ 4 /$.

\section{SUBBOUNDARIES AND CREEP RATE}

Since a small amount of strain on $7 y$ is due to boundary migration or destruction, the motion of individual dislocations is responsible for most of it. It could be directly studied in aluminium polycrystalline sheets with the help of in situ experiments, and this provided useful informations about the possible influence of subboundaries on the rate controlling process during stage II of creep $/ 5 /$.

The direct observation of moving dislocations through subgrains provides useful informations on their densities, on the effective obstacles to their motion, as well as the corresponding waiting times involved. Dislocations are observed to glide through the subgrains at temperatures between 80 and $200^{\circ} \mathrm{C}$. This could be deduced from the traces left at the foil surfaces by moving defects. The flight time through subgrains could be measured from dynamic recordings and was found to be shorter than $1 / 50 \mathrm{~s}$. The mean free path of the dislocations is larger than the subgrain size since moving dislocations are observed to cut through subboundaries. This is a much slower process and waiting times larger or much larger than $1 \mathrm{~s}$ can be measured at the boundaries. A local creep curve could be built from such observations in the following way: each dislocation which shears the subgrain provides an amount of strain $\varepsilon=b / L$ if $b$ is its Burgers vector. By counting the number of passing dislocations as a function of time, the curve of Fig. 6 could be established. It shows that successive groups of $5,4,1$ and 5 dislocations respectively, have been gliding through the observed subgrain (2 $\mu \mathrm{m}$ in diameter) during the observation period of $2000 \mathrm{~s}$. An average deformation rate of $7.5 \cdot 10^{-7} \mathrm{~s}^{-1}$ could be derived. This experiment illustrates the jerky nature of $\mathrm{glide}$ under such creep conditions $/ 18 /$. 
Since the rate at which the crystal creeps, seems to be directly connected to the cutting through mechanism of mobile dislocations through subboundaries, this process was studied in detail both experimentally and theoreticaliy. In situ experiments $/ 5 /$ and pinned dislocation arrangements $/ 3 /$ show that a crosslip mechanism is involved for dislocation insertion or extraction. The critical event in extraction is the breaking of the first node by the escaping dislocation. Orders of magnitude of the critical stress have been computed $/ 5 /$ and though they are smaller than the Orowan stress, they are much larger than the applied one.

The barriers to dislocation motion for high temperature creep in aluminium are the subboundaries. They are constructed as straining proceeds. In the same time, the crystal builds up large local internal stresses which add to the applied stress and help dislocation emission at priviledged points in the boundaries.

Acknowledgements: This work is supported by "Fonds National Suisse" and "ATP Internationale du CNRS". The authors acknowledge several fruitful discussions with J. Bonneville.

\section{REFERENCES}

/1/ M. Carrard and J.L. Martin in "Creep and Fracture of Engineering Materials and Structures", Ed. B. Wilshire and D.J. Owen, Pinebridge Press, Swansea U.K., (1984), p. 27

12/ D. Caillard and J.L. Martin, Acta Met. 30 (1982) 437

/3/ M. Morris and J.L. Martin, Acta Met. 32 (1984) 549

/4/ D. Caillard and J.L. Martin, Acta Met. 30 (1982) 791

/5/ D. Caillard and J.L. Martin, Acta Met. 31 (1983) 813

/6/ G. Champier, L. Kubin and J.L. Martin in "Dislocations et Déformation Plastique", Les Editions de Physique, Paris (1980), p. 405

17/ J.P. Hirth and J. Lothe in "Theory of Dislocations", 2nd Ed., John Wiley, (1982), p. 697

18/ S. Amelinckx, Acta Met., 6 (1958) 34

/9/ D. Caillard and J.L. Martin in "The Structure and Properties of Crystal Defects", Ed. V. Paidar and L. Lejcek, Materials Science Monograph 20, Elsevier, $(1984)$, p. 447

/10/ C.J. Ball and P.B. Hirsch, Phil. Mag. 46 (1955) 1343

/11/ M. Morris, Doctorate Thes is no 520, EPF Lausanne, 1984

/12/ S.H. Suh, J.B. Cohen and J. Weertman, Metal1. Trans., A14 (1983) 117

113/ M. Morris and J.L. Martin, Acta Met. Accepted for publication

/14/ M.M. Myshlyaev, D. Caillard and J.L. Martin, Scripta Met., 12 (1978) 157

/15/ J. Washburn and E.R. Parker, J. Metals, 194 (1952) 1076

/16/ S.F. Exell and D.H. Warrington, Phi1. Mag. 26 (1972) 1121

/17/ M. Morris, D. Masson, B. Senior and J.L. Martin, Scripta Met., 17 (1983) 687

/18/ D. Caillard. Doctorate Thesis, UPS Toulouse, 1980 